\title{
Asfiktik Bebeklerde Antitrombin III Düzeyleri ve Dissemine İntravasküler Koagülasyon'la İlişkisi
}

\author{
Bahri EImas', Neşide Çetin ${ }^{2}$
}

\begin{abstract}
$\ddot{\mathbf{O z}}$
Birçok asfiktik bebeğin hastaneye kabulünde kanama sorunu bulunurken bazılarında takip sırasında dissemine intravasküler koagülasyon (DİK) gelişmektedir. DİK tedavisinde temel prensibin altta yatan problemin düzeltilmesi olduğu bilinmekle birlikte pre-DİK döneminde tanı konulması, tedavisinin başarısı açısından en önemli faktördür. Çeşitli çalışmalar ve hayvan deneyleri DİK tablosu gelişmeden önce koagulasyon faktörlerinde bazı değişimler olduğunu göstermektedir. Bu değișikliklerden birisi de antitrombin III ( AT III) düzeylerinin azalmasıdır. $\mathrm{Bu}$ çalışmada; asfiktik bebeklerde AT III düzeyleri ve AT III'ün asfiktik bebeklerde gelișen DİK ile ilişkisinin araștırılması amaçlanmıștır. Çalıșmaya doğumu izleyen ilk saatlerde çeşitli derecelerden asfiksiye maruz kalmış 50 ve zamanında komplikasyonsuz doğmuş sağlıklı 20 bebek alındı. Her iki grupta doğumu izleyen ilk 12 saatte AT III, PT, PTT, D dimer düzeyi ve trombosit sayısı çalışıldı. Takibinde DİK gelişen ve gelişmeyen bebeklerin başlangıç değerleri karşılaştırılarak AT III'ün DİK'in erken tanısındaki değeri araştırıldı. Asfiktik bebeklerin kontrol grubuna göre AT III düzeyleri ve trombosit sayıları düşük, PT, PTT ve D dimer düzeyleri ise anlamlı şekilde yüksek idi. Takibi sırasında DİK gelişen bebeklerin başlangıçta alınan AT III düzeyleri (14.01 \pm 5.11$)$, DİK gelişmeyenlere $(19.03 \pm 2.74)$ göre anlamlı şekilde düşük idi $(\mathrm{p}<0.05)$. D dimer yüksekliği gösteren bebeklerin oranı DİK gelişen grupta \%100 iken DİK gelişmeyen grupta $\% 55$ olarak bulundu ve fark anlamlı idi $(\mathrm{p}<0.05)$. İki grubun PT, PTT ve trombosit sayıları arasında anlamlı bir fark bulunmadı. Sonuç olarak; asfiktik bebeklerde AT III düzeyleri sağl1klı bebeklere göre düșüktür ve DİK şüphesi bulunan asfiktik bebeklerde AT III düzeyi tayininin, D dimer düzeyleri ile birlikte pre-DİK evresinin bir göstergesi olabileceğini düşündürmektedir.
\end{abstract}

Yayın Bilgisi

Anahtar Kelimeler: Asfiksi, Antitrombin III, Dissemine İntravasküler Koagülasyon,

Yenidoğan, Koagülasyon Parametreleri

\section{Antithrombin III Levels in Asphyxiated Newborns and Relation to Disseminated Intravascular Coagulation}

Bahri Elmas ${ }^{1}$, Neșide Çetin ${ }^{2}$

\begin{abstract}
While many asphyxiated newborn are admitted to the hospital with bleeding problems, disseminated intravascular coagulation (DIC) develops in some cases during follow-up. Although it is known that the basic principle in the treatment of DIC is to correct the underlying problem, diagnosis in pre-DIC is the most important factor in the success of treatment. Various studies and animal experiments show that there are some changes in coagulation factors before DIC develops. One of these changes is the reduction of antithrombin III (AT III) levels. The aim of this study was to investigate the association of AT III levels with DIC in asphyxiated infants. Fifty infant sex posed to various degrees of asphyxia in the first hours following birth and 20 healthy infants born without complications were included in the study. In both groups, AT III, PT, PTT, D dimer levels and platelet counts were studied during the first 12 hours after birth. Early AT III values of developing and non-developing infants with DIC were compared and the value of AT III early diagnosis of DIC was investigated. Asphyxiated infants had lower levels of AT III and platelet counts and significantly higher PT, PTT and D dimer levels than control group. The initial AT III levels $(14.01 \pm 5.11)$ of the infants with DIC were significantly lower than those without DIC $(19.03 \pm 2.74)(p<0.05)$. The D dimer height ratio was $100 \%$ in the developing group, $55 \%$ in the non-developing group, and the difference was significant $(\mathrm{p}<0.05)$. No significant difference was found between PT, PTT and platelet counts of two groups. As a result; the AT III levels in asphyxiated infants are lower than in healthy infants and the AT III level determination in asphyxiated infants with DIC suspicion may be indicative of the pre-DIC status together with $\mathrm{D}$ dimer levels.
\end{abstract}

Article Info

Received:05.01.2018

Accepted:31.01.2018

Online Published:31.03.2018

DOI: $10.26453 /$ otjhs.375116

Keywords: Asphyxia, Antithrombin III, Disseminated Intravascular Coagulation,

Newborn, Coagulation Parameters

1Yard. Doç. Dr. Bahri ELMAS, Sakarya Üniversitesi Tıp Fakültesi, Pediatri Anabilim Dalı, Sakarya

${ }_{2}$ Prof. Dr. Neşide ÇETIN, Emekli 


\section{GíRIŞ}

Perinatal asfiksi, beyin hipoksisi ve iskemik olayların bir sonucu olarak yenidoğan döneminde ortaya çıkan anormal nörolojik bulguları tanımlamaktadır ${ }^{1,2}$. Siklığının 1000 canlı doğumda 1-6 arasında olduğu bildirilmektedir ${ }^{3}$. Asfiktik yenidoğanlarda, kanama bulguları ile veya kanama bulguları olmadan koagulasyon anormallikleri rapor edilmiştir. Asfiktik bebekler; koagulasyon faktörlerinin yetersiz sentezi, damar duvarı veya doku zedelenmesine bağlı olarak koagülasyon kaskadının başlatılması ve koagülasyon faktörlerinin tüketimi, trombositlerin yetersiz salınımı veya yaşam sürelerinin kısalması gibi nedenlerle dissemine intravasküler koagülasyona (DİK) eğilimlidirler ${ }^{2,4,5}$.

Dissemine intravasküler koagülasyon; normal koagülasyon mekanizmasının kontrolsüz ve sistematik aktivasyonu ile karakterizedir. Koagülasyon kaskadı aktive olduğu zaman bir proteaz inhibitörü olan antitrombin III (AT III) aktive olmuş pıhtılaşma faktörlerinin inaktivasyonunda rol oynar ${ }^{6,7}$. DİK sirasında AT III seviyesi ölçümünün, koagulasyon proçesinin devam edip etmediği ve tedavinin etkinliğinin anlaşılmasında önemli bir indikatör olduğu bildirilmiştir ${ }^{8-10}$. Tedavi ile AT III düzeylerinin yükselmesinin tüketim proçesinin kontrol altına alındığını gösterdiği iddia edilmiştir ${ }^{10}$. AT III' ün asfiktik yenidoğanlardaki serum düzeyleri ve DİK'in erken tanısındaki rolü üzerine yeterli çalışma yapılmamıştır.

Çalışmamızda asfiksiye maruz kalmış bebeklerde AT III düzeylerinin DİK'in erken tanısındaki öneminin belirlenmesi amaçlanmıștır.

\section{MATERYAL VE METOD}

Çalışmaya Mart 1998 ve Ağustos 1998 tarihleri arasında Erciyes Üniversitesi Tip Fakültesi Yenidoğan ünitesine doğumu izleyen ilk saatlerde başvuran asfiksiye maruz kalmıș 50 ve kontrol grubu olarak Erciyes Üniversitesi Araştırma ve Uygulama Hastanesinde zamanında komplikasyonsuz doğmuş, doğum şekli ve cinsiyetleri asfiktik gruba benzer sağlıklı 20 bebek alındı. Asfiksi tanısında Sarnat\&Sarnat'1n kriterleri kullanıldı ve asfiktik bebekler grade I, II, ve III olarak gruplandırıldı. Her iki grupta doğumu izleyen ilk 12 saatte, AT III, PT, PTT, D, dimer düzeyi ve trombosit sayıları çalışıldı. Takibi sırasında ilk yedi gün içinde klinik ve laboratuvar bulgularla DİK tanıs1 konulan ve konulmayan bebeklerin başlangıçta alınan değerleri karşılaştırılarak AT III' ün DİK' in erken tanısındaki değeri araştırıldı.

AT III tayini Beckman AT3 (P/N 441480) kiti kullanılarak nefelometrik yöntemle, PT ölçümü SIGMA DIAGNOSTICS TromboMAX WITH CALCIUM, PTT ölçümü Activated partial thromboplastin time ( APTT) SIGMA A-1801 kiti kullanılarak manuel yöntemle ve D dimer 
düzeyi ölçümü Sigma Diagnostics ACCUCLOT D- dimer kiti kullanılarak kalitatif yöntemle yapıldı. Grupların karşıllaştırılmasında student t testi, ANOVA varyans analizi ve Ki-kare testleri kullanıldı. $\mathrm{P} \leq 0.05$ değerleri istatistiksel olarak anlamlı kabul edildi.

\section{BULGULAR}

Çalışma 50'si asfiktik 20'si sağlıklı olmak üzere 70 bebekte yapıldı. Bebeklerin 34'ü (\%48.5) k1z, 36's1 ( \%51.4) erkek idi. Cinsiyet ve doğum şekli her iki grupta benzerdi. Sarnat\&Sarnat'ın sınıflamasına göre hastaların 8'i (\%16) grade I, 25’i ( \%50) grade II ve 17’si ( \%34) grade III idi.

Asfiktik grubun ortalama AT III düzeyleri kontrol grubunun AT III düzeylerine göre belirgin olarak düşük bulundu $(\mathrm{p}<0.05)$. Asfiktik grubun ortalama PT ve PTT değerleri kontrol grubunun değerlerinden uzun bulundu ( $\mathrm{p}<0.05)$. Ortalama trombosit sayıları asfiktik grupta kontrol grubuna göre düşük ve aralarındaki fark istatistiksel olarak anlamlı bulundu ( $\mathrm{p}<0.05)$. Asfiktik grubun 33' ünde (\%66), kontrol grubunun 3' ünde (\%15) D dimer düzeyi $250 \mathrm{ng} / \mathrm{mL}$ üzerinde bulundu. İki grup arasındaki fark istatistiksel olarak anlamlı idi $(p<0.05)$. Asfiktik ve kontrol grubu demografik verileri, AT III ve koagülasyon parametreleri Tablo 1' de gösterilmiştir.

Asfiktik bebeklerin ortalama AT III değerleri asfiksinin derecesine göre karşılaştırıldığında; grade I asfiktik bebekler ile kontrol değerleri arasında anlamlı fark bulunmazken grade II ve III asfiktik bebeklerin AT III değerleri kontrol grubundan anlamlı şekilde düşük bulundu $(\mathrm{p}<0.05)$ (Tablo 2).

Tablo 1. Asfiktik ve kontrol grubu AT III ve koagülasyon parametreleri

\begin{tabular}{lccc}
\hline & Asfiktik grup & Kontrol grubu & $p$ \\
& $\mathrm{n}: 50$ & $\mathrm{n}: 20$ & \\
\hline Cinsiyet, K/E & $28 / 22$ & $8 / 12$ & $>0.05$ \\
Doğum şekli, & $36 / 14$ & $14 / 6$ & $>0.05$ \\
Normal/Sezaryen & & & \\
AT III, mg/dL & $17.904 \pm 4.051$ & $24.050 \pm 3.410$ & $<0.05$ \\
PT, sn & $18.9 \pm 11.1$ & $13.9 \pm 1.9$ & $<0.05$ \\
PTT, sn & $55.2 \pm 17.1$ & $43.3 \pm 7.5$ & $<0.05$ \\
Trombosit sayıs1, & $215420 \pm 91878$ & $351550 \pm 91026$ & $<0.05$ \\
/mm ${ }^{3}$ & & & \\
D dimer düzeyi, & $33 / 17$ & $3 / 17$ & $<0.05$ \\
ng/mL & & & \\
$(>250 /<250)$ & & & \\
\hline
\end{tabular}

Tablo 2. Asfiktik ve kontrol grubu bebeklerin grade'lerine göre AT Ш değerleri.

\begin{tabular}{|c|c|c|c|c|c|}
\hline & $\begin{array}{c}\text { Grade I } \\
\mathrm{n}: 8\end{array}$ & $\begin{array}{c}\text { Grade II } \\
\mathrm{n}: 25\end{array}$ & $\begin{array}{c}\text { Grade III } \\
\mathrm{n}: 17\end{array}$ & $\begin{array}{c}\text { Kontrol } \\
\text { n:20 }\end{array}$ & $p$ \\
\hline AT III, & $20.87 \pm$ & $18.80 \pm 2.5$ & $15.18 \pm 4.6$ & $24.05 \pm 3.4$ & $<0.0$ \\
\hline $\mathrm{mg} / \mathrm{dL}$ & $3.27^{\mathrm{ab}}$ & $9^{\mathrm{cd}}$ & $8^{\mathrm{cd}}$ & $1^{\mathrm{ab}}$ & 5 \\
\hline
\end{tabular}
a:Grade III'e göre farkl, b:Grade II'ye göre farkl, $\boldsymbol{c}$ : Kontrol grubuna göre farkl, d:Grade I'e göre farklı

Tablo 3. DİK gelişen, gelişmeyen ve kontrol gruplarının başlangıç AT Ш değerleri.

\begin{tabular}{|c|c|c|c|c|}
\hline & \multicolumn{3}{|c|}{ DİK } & \multirow[t]{2}{*}{$\mathrm{P}$} \\
\hline & $\begin{array}{c}\text { DİK gelişen } \\
\text { n:12 }\end{array}$ & $\begin{array}{c}\text { gelişmeyen } \\
\mathrm{n}: 38\end{array}$ & $\begin{array}{c}\text { Kontrol } \\
\mathrm{n}: 20\end{array}$ & \\
\hline $\begin{array}{l}\mathrm{AT} \\
\mathrm{mg} / \mathrm{dL}\end{array}$ & $14.01 \pm 5.11^{\mathrm{ab}}$ & $19.03 \pm 2.74^{\mathrm{ac}}$ & $24.05 \pm 3.41^{b c}$ & $<0.05$ \\
\hline $\begin{array}{l}\text { D dimer, } \\
\mathrm{ng} / \mathrm{mL}\end{array}$ & & & & \\
\hline$(>250 /<250)$ & $12 / 0$ & $21 / 17$ & $3 / 17$ & $<0.05$ \\
\hline
\end{tabular}


Takipleri sirasında 12 (\%24) hastada DİK bulgusu tespit edildi. DİK gelişen bebeklerin başlangıç AT III değerleri DİK gelişmeyen gruptan düşük, DİK gelişmeyen grubun AT III değerleri de kontrol grubuna göre anlamlı şekilde düşük bulundu $(\mathrm{p}<0.05)$. $\mathrm{D}$ dimer yükseklik oranları DİK gelişen grupta DİK gelişmeyen gruba göre yüksek bulundu $(p<0.05)$. DİK gelişen ve gelişmeyen grupların PT, PTT ve trombosit sayıları arasında fark bulunmadı. DİK gelişen ve gelişmeyen grubun AT III ve koagülasyon parametreleri Tablo 3' de gösterilmiştir.

\section{TARTIŞMA}

Çalışmamızda asfiktik bebeklerde henüz DİK bulguları gelişmemişken koagülasyon testleri, trombosit sayıları ve AT III düzeylerinde anormallikler tespit edildi ve bu bulguların asfiksi derecesi ile daha belirgin hale geldiği gözlendi. Asfiktik grubun AT III düzeyleri kontrol grubuna göre belirgin olarak düşük bulundu. Peters ve ark., 16 sağlıklı term, 10 preterm ve 16 RDS'li preterm infantın 106 plazma örneğinde AT III düzeylerinin; sağglıklı term yenidoğanlara göre sağlıklı ve RDS'li pretermlerde, sağlıklı pretermelere göre ise respiratuvar distres sendromlu pretermlerde daha düşük olduğunu bildirmişlerdir ${ }^{11}$. Matür asfiktik bebeklerde AT III düzeyleri ile ilgili literatürde çalışma bulunamadığından sonuçlarımızı karşılaştırma imkanımı olmamıştır.
Çalışmamızda asfiktik grubun PT ve PTT değerleri kontrol grubundan yüksek bulunmuştur. Fichera ve ark., koagülopati riskinden dolayı asfiksiye maruz kalan yenidoğanlarda trombosit sayıs1, PT, PTT, fibrinojen, faktör V, VIII ve fibrin y1k1m ürünlerinin çalışılması gerektiğini vurgulamışlardır ${ }^{12}$. Öncel ve ark. tarafından yapılan çalışmada asfiktik bebeklerde sağlıklı bebeklere göre PT, APTT, D Dimer düzeyleri yüksek ve trombosit sayıları anlamlı şekilde düşük bulunmuştur ${ }^{2}$. Çalışmamızda asfiktik bebeklerde PT ve PTT değerlerinin yüksek bulunmasının AT III' e benzer şekilde hipoksinin etkisi ile karaciğerden koagülasyon faktörlerinin yetersiz sentezi veya kullanımdaki artışa bağl1 olduğu düşünülmüştür.

Asfiktik grupta D dimer düzeyi yüksek olan bebeklerin oranı kontrol grubundan yüksek bulunmuştur. Chadd ve ark., asfiktik bebeklerin sağlıklı term bebeklere göre trombosit sayılarının düşük, fibrin yıkım ürünlerinin yüksek ve trombin zamanlarının uzamış olduğunu tespit etmişler ve bunların asfiksi derecesi arttıkça daha belirgin hale geldiğini bildirmişlerdir ${ }^{13}$. Schander ve ark., asfiktik yenidoğanların kord kanı örneklerinde plazminojen seviyelerinin sağlıklı gruba göre anlamlı şekilde düşük, fibrin yıkım ürünleri ve fibrin monomerlerinin ise yüksek olduğunu tespit etmişlerdir ${ }^{14}$. Sonuçlarımız bu iki çalışmanın sonuçları ile uyumlu bulunmuş ve asfiksi derecesi arttıkça D dimer düzeyi yüksek 
bebeklerin oranında artma olduğu tespit edilmiştir.

Asfiktik bebeklerde AT III düzeyindeki düşme, D Dimer düzeyindeki yükselme ile birlikte değerlendirildiğinde, daha çok prokoagülan sisteminin aktivasyonu ile kullanımdaki artışı düşündürmektedir. Ağır asfiktiklerde AT III düzeylerinin daha düşük olması bu anormalliklerin asifksi ile ilişkisini gösteren önemli bir bulgu olarak değerlendirilmiştir. PT ve PTT değerlerindeki yükselmenin de aynı mekanizma ile koagülasyon faktör seviyelerindeki düşmeye bağlı olduğu düşünülmüştür.

Asfiktik bebeklerde trombosit sayıları düşük olarak bulunmuştur. Trombosit sayılarındaki düşmenin hipoksinin kemik iliği üzerindeki süpresyon etkisinin yanında bu bebeklerde sıklıkla izlendiği belirtilen DİK tablosuna bağlı olabileceği düşünülmüştür. AT III, D dimer, PT ve PTT'deki anormalliklerle birlikte değerlendirildiğinde trombositopeninin büyük oranda koagülasyon sisteminin aktivasyonuna bağlı olduğunu düşündürmektedir.

Grade I asfiktik grupta trombosit sayıları kontrol değerlerine yakın olarak bulunmuştur. Mc Donald ve ark., kısa süreli asfiksiye maruz birakılan farelerde dalaktan hipoksiye cevap olarak genç trombositlerin salınmasına bağlı trombosit sayılarında artma, uzun süreli asfiksiye maruz kalanlarda ise belirgin azalma olduğunu tespit etmişlerdir ${ }^{15}$. Boutaybi ve ark., tarafından yapılan çalışmada perinatal asfiksi sonrası yenidoğanlarda erken başlangıçlı trombositopeni geliştiği ve PT ve laktat düzeyleri ile bağımsız olarak ilişkili olduğu bildirilmiştir ${ }^{16}$. Çalışmamızın sonuçları bu bulgularla uyumlu bulunmuştur.

Takipleri sırasında DİK gelişen bebeklerin başlangıçta alınan AT III değerleri DİK gelişmeyen grup ve kontrol grubundan düşük bulunmuştur. DİK gelişmeyen gurubun AT III değerleri de kontrol grubuna göre anlamlı şekilde düşük bulunmuştur. Bick ve ark., AT III'ün DİK'de erken ve duyarlı bir tanı aracı olduğunu ve fibrin yıkım ürünleri için kullanılan yöntemlerin sensitif olmaması nedeni ile AT III seviyelerinin DİK'li hastalarda tüketim ve tüketimin tedavisinin kontrolü için etkili, basit ve güvenilir bir gösterge olduğunu iddia etmişlerdir 9. Aynı araştırmacılar başka bir çalışmalarında AT III düzeylerinin DİK'in erken dönemlerinde anlamlı olarak düşük olduğunu saptamışlardır ${ }^{17}$. Yaş grupları farklı olmakla birlikte çalışmalarımızın sonuçları bu çalışmalarla uyumlu bulunmuştur ve AT III düzeylerinin DİK'in erken evrelerinde bir gösterge olabileceğini düşündürmektedir.

D dimer düzeyi yüksek olan bebeklerin oranı DİK gelişen grupta DİK gelişmeyen gruba göre yüksek bulunmuştur. Takagi ve ark., DİK ve pre- DİK ( DİK başlamadan önceki yedi günlük dönem) evresindeki hastalarda D-dimer düzeylerinin belirgin olarak yükseldiğini tespit etmişler ve $\mathrm{D}$ dimer düzeylerinin pre-DİK 
evresinde tanıda kullanılabilecek bir gösterge olduğunu bildirmişlerdir ${ }^{18}$. Bick ve arkadaşları D dimer düzeylerinin AT III ve fibrinopeptid-A ile birlikte kullanıldığ 1 zaman DİK'in erken tanısında önemli bir belirleyici olduğunu bildirmişlerdir ${ }^{19}$. Çalışmamızın sonuçları bu iki çalışmanın sonuçları ile uyumlu olarak, D dimer düzeylerinin de AT III düzeyleri gibi pre-DİK evresinin bir göstergesi olabileceğini göstermektedir. PT, PTT ve trombosit sayılarında asfiktik bebeklerde anormallikler bulunmakla birlikte DİK'in erken evrelerinde herhangi bir değişiklik olmadığı izlenmiştir.

Sonuç olarak asfiktif term bebeklerde AT III düzeylerinin sağlıklı term bebeklere göre daha düşük olduğu saptanan bu çalışmamız, AT III ve $\mathrm{D}$ dimer düzeylerinin asfiktif bebeklerde gelişen DİK' in erken evrelerinde bir gösterge olarak kullanılabileceğini düşündürmektedir.

\section{KAYNAKLAR}

1. Bona E, Hagberg H, Løberg EM, Bågenholm R, Thoresen M. Protectiveeffects of moderatehypothermiaafterneonatalhypoxiaischemia: short- andlong-termoutcome. Pediatr Res. 1998;43(6):738-45.

2. Oncel MY, Erdeve O, Calisici E, et al. Theeffect of whole-body cooling on hematological and coagulation parameters in asphyxic newborns. Pediatr HematolOncol. 2013;30(3):246-52.
3. Vannucci RC. Hypoxic-ischemic encephalopathy. Am J Perinatol. 2000;17(3):113-20.

4. Küçüködük Ş. Yenidoğan ve Hastalıkları (1. Bask1). Feryal matbaası, Ankara 1994, ss 341- 381

5. Phelan JP, Kirkendall C, Korst LM, Martin GI. Nucleated red blood cell and platelet counts in asphyxiated neonates sufficient to result in permanent neurologic impairment. J Matern Fetal Neonatal Med. 2007;20(5):37780.

6. Pugh M. DIC screening in the newborn. Neonatal Netw. 1997;16(7):57-60.

7. Choudhry VP, Thavaraj V, Saraya AK. Disseminated intravascular coagulation: diagnosis and current therapy. Indian Pediatr. 1990;27(3):280-8.

8. Mammen EF, Farag AA. The Role of Antithrombin III in DIC. Biologia\&Clinica Hematologica 1987;9(2): 69-73.

9. Bick RL, Dukes ML, Wilson WL, Fekete LF. Antithrombin III(AT-III) as a diagnostic aid in disseminated intravascular coagulation. Thromb Res. 1977;10(5):721-9.

10. Bick RL. Clinical relevance of antithrombin III. Semin Thromb Hemost. 1982;8(4):27687.

11. Peters M, Jansen E, ten Cate JW, Kahlé LH, Ockelford P, Breederveld C. Neonatal antithrombin III. $\mathrm{Br} \quad \mathrm{J}$ Haematol. 1984;58(4):579-87. 
12. Fichera A, Praticò G, Sciacca F. [Neonatal hypoxia and hemocoagulative changes]. Pediatr Med Chir. 1989;11(6):643-7.

13. Chadd MA, Elwood PC, Gray OP, Muxworthy SM. Coagulation defects in hypoxic full-term newborn infants. Br Med J. 1971;4(5786):516-8.

14. Schander K, Rehm A, Niesen M. [Blood coagulation activity and fibrinolysisin umbilical vein blood of healthy and asphyxiated newborn infants]. Fortschr Med. 1977;95(22):1477-81.

15. McDonald TP, Cottrell M, Clift R. Effects of short-term hypoxia on platelet counts of mice. Blood. 1978;51(1):165-75.

16. Boutaybi N, Steggerda SJ, SmitsWintjensVE, vanZwet EW, Walther FJ, Lopriore E. Early-onset thrombocytopenia in near-term and term infants with perinatal asphyxia. Vox Sang. 2014;106(4):361-7.

17. Bick RL, Bick MD, Fekete LF. Antithrombin III patterns in disseminated intravascular coagulation. Am J Clin Pathol. 1980;73(4):577-83.

18. Takagi $\mathrm{M}$, Wada $\mathrm{H}$, Tanigawa $\mathrm{M}$, et al. [Measurement of FDP-D-dimer in DIC and pre-DIC]. Rinsho Byori. 1990;38(7):806-12.

19. Bick RL, Baker WF. Diagnostic efficacy of the D-dimer assay in disseminated intravascular coagulation (DIC). ThrombRes. 1992;65(6):785-90. 